\title{
The role of dynamic contrasts in the $L 2$ acquisition of Spanish past tense morphology*
}

\author{
LAURA DOMÍNGUEZ \\ University of Southampton \\ NICOLE TRACY-VENTURA \\ University of Southampton \\ MARÍA J. ARCHE \\ University of Greenwich \\ ROS AMOND MITCHELL \\ University of Southampton \\ FLORENCE MYLES \\ University of Essex
}

(Received: October 20, 2011; final revision received: May 23, 2012; accepted: July 2, 2012)

This study examines the second language acquisition of Spanish past tense morphology by three groups of English speakers (beginners, intermediates and advanced). We adopt a novel methodological approach - combining oral corpus data with controlled experimental data - in order to provide new evidence on the validity of the Lexical Aspect Hypothesis (LAH) in L2 Spanish. Data elicited through one comprehension and three oral tasks with varying degrees of experimental control show that the emergence of temporal markings is determined mainly by the dynamic/non-dynamic contrast (whether a verb is a state or an event) as beginner and intermediate speakers use Preterit with event verbs but Imperfect mainly with state verbs. One crucial finding is that although advanced learners use typical Preterit-telic associations in the least controlled oral tasks, as predicted by the LAH, this pattern is often reversed in tasks designed to include non-prototypical (and infrequent) form-meaning contexts. The results of the comprehension task also show that the Preterit-event and Imperfect-state associations observed in the production data determine the interpretation that learners assign to the Preterit and the Imperfect as well. These results show that beginner and intermediate learners treat event verbs (achievements, accomplishments and activities) in Spanish as a single class that they associate with Preterit morphology. We argue that dynamicity contrasts, and not telicity, affect learners' use of past tense forms during early stages of acquisition.

Keywords: Lexical Aspect Hypothesis, second language acquisition, Imperfect, Spanish, learner corpora

\section{Introduction}

Although the acquisition of past tense morphology (e.g. Imperfect and Preterit) is one of the most investigated areas in Second Language Acquisition (SLA) research, the role that lexical aspect plays in the acquisition of these forms in the second language (L2) remains currently under debate. The leading hypothesis, i.e. the Lexical Aspect Hypothesis (LAH) (Andersen, 1986, 1991; Andersen \& Shirai, 1994; Bardovi-Harlig, 2000), argues that certain

* This study has been supported by the UK Economic and Social Research Council (ESRC) research grant RES-062-23-1075 and is part of the Spanish Learner Language Oral Corpora (SPLLOC) project. We would like to thank all the people involved in the project including fieldworkers and transcribers, and in particular schools and colleges in the UK and Spain which kindly agreed to participate in the study. We are also grateful to three anonymous reviewers for their useful comments and suggestions for improvement.

1 Analyses based on the parameterised nature of Aspect (Slabakova, 1999; Smith, 1991) have lent added theoretical interest to this problem as the acquisition of $\mathrm{L} 2$ aspect is an additional area where, for example, claims about the possibility of parameter re-setting and the acquisition of functional features among L2 learners can be tested (see Montrul \& Slabakova, 2002; Slabakova \& Montrul, 2003). form-meaning associations (i.e. telic-Preterit and atelicimperfect) guide the emergence of past tense forms in L2 grammars. ${ }^{1}$ This hypothesis is especially relevant for the L2 acquisition of Spanish since temporal and aspect distributions (e.g. the Preterit/Imperfect contrast) are expressed through specific morphological forms in this language.

The validity of the LAH for the L2 acquisition of Spanish has not been satisfactorily demonstrated partly because of methodological issues affecting the design of the tasks employed (Camps, 2005; Comajoan, 2006; Montrul \& Salaberry, 2003; Salaberry, 2008). There are two specific issues regarding the experimental design used in studies assessing the LAH which appear to be especially problematic. First, in some contexts the structure of a narrative (background and foreground) and the inherent aspectual properties of a predicate (telic and atelic) make opposite predictions regarding what morphological form (Preterit or Imperfect) is more likely to be used. Although this is potentially an ideal scenario in which to test the predictions of the LAH, such contexts are rare in naturally occurring discourse and therefore are difficult to test using uncontrolled narrative tasks. Second, because

Address for correspondence:

Laura Domínguez, University of Southampton, Modern Languages, Southampton SO17 1BJ, UK

ldo@soton.ac.uk 
existing data have been elicited using either production or comprehension tasks only, studies using combined evidence from both types of tasks are not available. This is despite claims (e.g. Slabakova, 2001) that data elicited through carefully designed experiments are necessary to achieve a full understanding of L2 speakers' competence in this grammatical domain.

The current study provides new insights into the role that lexical aspect plays in the acquisition of Spanish as a second language by explicitly addressing these two methodological issues. We will show how the combination of a specially designed corpus of L2 Spanish and a comprehension task can provide more complete evidence of L2 learners' linguistic competence regarding Spanish past tense morphology. Crucial in this study is the fact that the corpus of L2 Spanish has been built using three different oral elicitation tasks with increasingly controlled structure (personal interview, semi-controlled impersonal narrative and controlled storytelling task). These three tasks were administered to the same group of 60 learners of Spanish whose first language (L1) was English. Through the use of this specific methodology we are able to show that some effects of lexical class are indeed clearly visible in the personal narrative task, a task widely used in previous literature testing the LAH, but that this task alone cannot be used as definite evidence to support this hypothesis. In this paper we will present combined results which show that although certain verbal features (dynamicity in particular) seem to play a role from the earliest stages of acquisition, the learners targeted possess a more sophisticated knowledge of aspectual morphology in Spanish than that predicted by the LAH.

This paper is structured as follows. Section 2 provides the theoretical background on how aspect is represented in Spanish and introduces the principles of the Lexical Aspect Hypothesis. Section 3 discusses the motivation for the present study focussing on several methodological inconsistencies in previous research. Section 4 introduces the production study and the rationale for the three tasks employed. Results from these three tasks, and in particular those elicited in non-prototypical contexts, are discussed in this section as well. Section 5 introduces the comprehension study and discusses the results elicited by a sentence-context preference matching task. Section 6 discusses the results and their implications for both theorising and methodological debates in formal SLA research. Section 7 presents the conclusions.

\section{Aspect marking in native and non-native Spanish}

Aspect provides information about the temporal development of an eventuality including whether events are finished, about to start or in progress. In Spanish, these properties are grammaticalised in the past tense in morphological forms known as Preterit, when the interval of time during which the eventuality takes place is finished (perfective), and Imperfect, when referring to intervals of time that are still in progress and are unfinished (imperfective):

(1) a. When Sue arrived (finished), my brother was cleaning (unfinished) the house.

b. Cuando Sue llegó PRET $_{\text {(finished), mi hermano }}$ limpiaba $_{\mathrm{IMP}}$ (unfinished) la casa.

The aspectual meaning of a sentence is also determined by the inherent lexical semantic properties of the verbal predicate (the verb and its complements) (Dowty, 1986; Smith, 1991; Tenny, 1994; Verkuyl, 1993). For instance, events such as "break" or "build a castle" have inherent endpoints (are regarded as telic) in contrast to events such as "sleep" or "sing" which denote actions which do not involve a culmination point (regarded as atelic) (see Depraetere, 1995; Smith, 1991). The examples in (2) show how the same Spanish verb can be either telic or atelic and used with both Preterit (PRET) and Imperfect (IMP) morphology. Telic and atelic interpretations depend on the internal argument of the verb. The English translations indicate how this is expressed with different morphosyntactic means in English (morphological affixes on the verbs in (2a) and (2b), or periphrasis in (2c) and (2d)).

(2) a. Marta corrió PRET $_{\text {PRT }}$ por el parque (durante/*en 15 minutos). atelic, perfective "Marta $\operatorname{ran}_{\mathrm{PAST}}$ in the park (for/*in 15 minutes)."

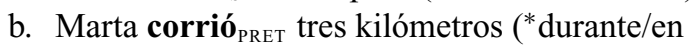
15 minutos). telic, perfective "Marta $\operatorname{ran}_{\mathrm{PAST}}$ three kilometres $\left({ }^{*}\right.$ for/in 15 minutes)."

c. Marta corría ${ }_{\mathrm{IMP}}$ por el parque (durante/*en 15 minutos). atelic, imperfective "Marta ran/used to/would run in the park (for $/{ }^{*}$ in 15 minutes)."

d. Marta corría ${ }_{\mathrm{IMP}}$ tres kilómetros (*durante/en 15 minutos). telic, imperfective "Marta ran/used to/would run three kilometres

( for/in 15 minutes)."

Because the aspectual interpretation of a verb is compositional (dependent on the whole VP and not just the verb), it is possible that the same verb can be interpreted as atelic in some contexts ((2a) and (2c)) but telic in others $((2 b)$ and $(2 d)) .{ }^{2}$ The examples above show that in Spanish the morphological form used can override the inherent aspectual value of events (atelic events with the Preterit in (2a) and telic events with the Imperfect in (2d)).

Four aspectual classes are typically distinguished according to the inherent aspectual properties of verbs:

\footnotetext{
2 The use of durante is grammatical in (2c) if it is interpreted as describing a habitual action.
} 


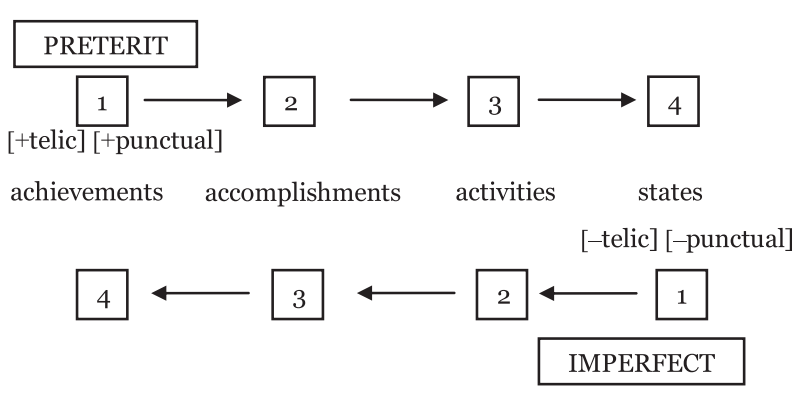

Figure 1. Expected pattern of spreading of Preterit and Imperfect forms across lexical classes.

states (be, love), activities (walk, swim), accomplishments (paint a picture, draw a circle) and achievements (break, die) (see Vendler, 1967). States are events that do not require an input of energy, do not have an inherent endpoint and have no internal structure; activities are events that have duration but lack an inherent endpoint; accomplishments are events that have duration and an inherent endpoint and achievements are events that have an inherent endpoint but do not have duration (they are instantaneous). The distinction between these four classes is based on the interaction of three different features: telicity, dynamicity and duration (Andersen, 1989; Comrie, 1976; Smith, 1991). Telic events (accomplishments and achievements) have inherent endpoints whereas atelic events (states and activities) lack inherent endpoints. Dynamic events (accomplishments, activities and achievements) have input of energy whereas non-dynamic events (states) lack input of energy. Finally, punctual events (achievements) happen instantaneously and have no duration.

The Lexical Aspect Hypothesis (LAH) (Andersen, 1986, 1991; Andersen \& Shirai, 1996) is based on Vendler's four-way verbal categorisation and was proposed to explain observed patterns in the use of tense and aspect morphology by second language speakers. According to this hypothesis, inherent aspectual properties of verbs guide the acquisition of tense and aspect morphology on the basis that certain correlations between morphological forms and aspectual properties of verbs (i.e. perfective-telic and imperfective-atelic) are prioritised in learner grammars (see Bardovi-Harlig, 2000; Salaberry, 2008, for extensive discussion on the role of the LAH in acquisition). More precisely, Imperfect and Preterit morphology are claimed to appear in a sequence of stages determined by the lexical properties of the verbal predicate so that perfective forms are expected to emerge with telic predicates (achievements and accomplishments) and spread to activities and finally to states later on. In contrast, imperfective forms are claimed to appear first with states and spread to activities and finally to accomplishments and achievements (see Figure 1).
The LAH assumes that the distribution of forms present in the input plays a fundamental role in the acquisition of aspect morphology based on both the Relevance Principle, i.e. learners will acquire the most relevant morphological form first (Bybee, 1985), and the Congruence Principle, i.e. learners will associate features which are semantically congruent such as telicity and perfectivity (Andersen, 1993; Andersen \& Shirai, 1994; Shirai, 1993, 1995; Shirai \& Kurono, 1998). The LAH also assumes an association between lexical class and grammatical marking based on prototype theory (Rosch, 1973, 1978) according to which each given category has its best exemplars, or prototypes, and a number of peripheral members, the nonprototypical exemplars, with fewer features in common. Shirai and Andersen (1995) argue that children first restrict the use of past tense morphology to the prototype of the category past (i.e. [+telic], [+punctual], [+result]) and restrict the use of progressive (which denotes the semantic features [+dynamic, - telic]) to activities and never to [-dynamic] predicates (i.e. states). In the case of L2 learners, it is hypothesised that learners would first associate one main meaning with each morphological form. These arguments assume the universality of the acquisition of perfective markers as children are said to show similar properties even if acquiring languages which encode aspectual distinctions in a different manner (although see Weist, 1989, for contradictory evidence). This is consistent with proposals which have argued that certain semantic distinctions (e.g. state versus process and punctual vs. non-punctual) are biologically programmed and emerge early in acquisition (e.g. Bickerton's (1981) Language Bioprogram Hypothesis) and that both children and adults tend to favour the use of certain lexical and grammatical aspect combinations. For instance, it has been observed that properties such as telic (punctual), perfective and past on the one hand and atelic (durative), imperfective and present on the other, are natural form-meaning associations (Comrie, 1976) and that they cluster together as the result of nonlinguistic cognitive constraints (see Wagner, 2010, for details). A large body of research has documented the existence of such prototypical combinations in children's early use of morphological forms, including studies examining Spanish-speaking children using both production (Jackson-Maldonado \& Maldonado, 2001) and comprehension (Grinstead, Pratt \& McCurley, 2009). However, experimental data testing children's comprehension of non-prototypical associations have confirmed that children can appropriately prefer nonprototypical form-meaning pairings in certain contexts and corroborates that prototypical associations are only tendencies observable in production data (Wagner, 2010; Grinstead et al. 2009). Taking this discussion into consideration we can summarise three main predictions of the LAH for L2 Spanish as follows: 
Table 6. Significance of the explanatory variables.

\begin{tabular}{|c|c|c|c|c|c|}
\hline & Df & $\begin{array}{l}\text { Residual } \\
\text { Deviance }\end{array}$ & Df & $\begin{array}{l}\text { Residual } \\
\text { deviance }\end{array}$ & $\begin{array}{l}p \\
(>\mid \text { Chi } \mid)\end{array}$ \\
\hline NULL & & & 47 & 638.22 & \\
\hline Proficiency & 3 & 53.03 & 44 & 585.19 & $<.001$ \\
\hline Task & 2 & 18.12 & 42 & 567.07 & .0001 \\
\hline Lexical Class & 3 & 431.08 & 39 & 135.99 & $<.001$ \\
\hline Proficiency: Task & 6 & 12.9 & 33 & 123.09 & .044 \\
\hline Proficiency: & & & & & \\
\hline Lexical class & 9 & 32.88 & 24 & 90.21 & .0001 \\
\hline $\begin{array}{l}\text { Task: Lexical } \\
\text { class }\end{array}$ & 6 & 68.07 & 18 & 22.14 & $<.001$ \\
\hline
\end{tabular}

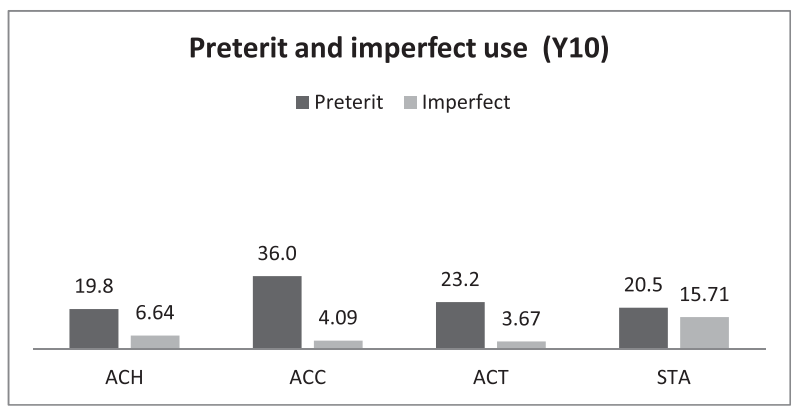

Figure 2. Average use of Preterit and Imperfect in the three oral tasks for beginner learners.

AND IMPERFECT WITH A PARTICULAR CLASS because the interaction between Task and Lexical Class is significant $(p<.001$, see last line of Table 6$)$.

The results for the Y10 group (see Figure 2) show that learners use Preterit with accomplishment verbs (36\%) more than with any other class, including achievements $(19.8 \%)$, due to the high number of instances of the verb ir "go" produced by this group of learners. This group of speakers uses the Preterit with the same frequency for all other classes (i.e. a Tukey post-hoc test shows that only the difference in use between accomplishments and achievements $(p=.001)$ and between accomplishments and activities ( $p=.005$ ) was significant). In clear contrast with the predictions of the $\mathrm{LAH}$, there were no differences between the use of Preterit in states and achievements $(p=.8)$. The use of imperfect, although very low, is significantly higher for states $(15.71 \%)$ than for any of the other three classes including activities $(p=.002)$, where the use is rather low (3.6\%). However, learners used the Preterit with states more often $(20.5 \%)$ than the Imperfect (15.7\%), a result which is not predicted by the LAH either. The difference in use between these two forms is not significant $(p=.33)$, which shows that although Imperfect is preferred with states more often than with

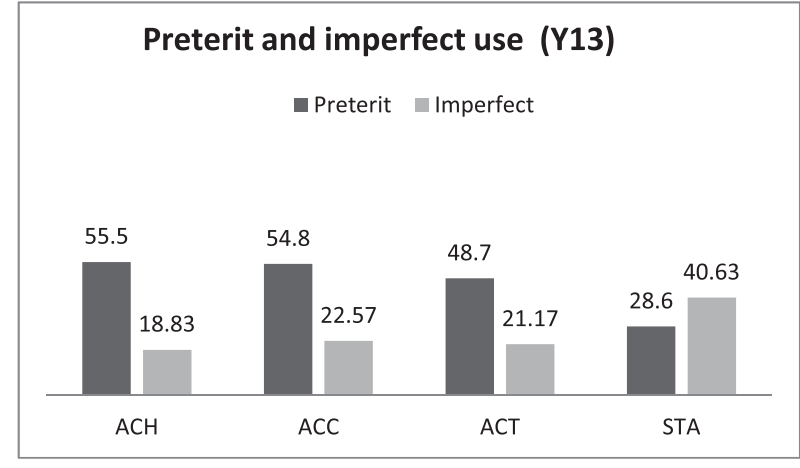

Figure 3. Average use of Preterit and Imperfect in the three oral tasks for intermediate learners.

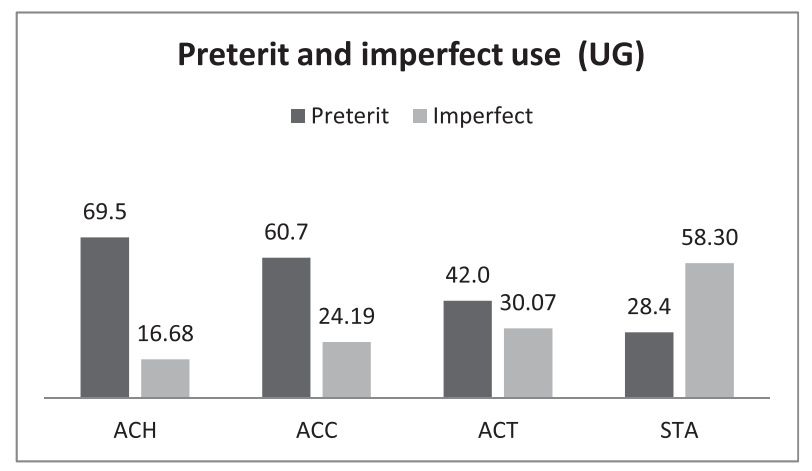

Figure 4. Average use of Preterit and Imperfect in the three oral tasks for advanced learners.

any other class, Preterit is used with states with similar frequency.

The results for the Y13 intermediate group show a clear increase in the use of Preterit and Imperfect forms (see Figure 3). This increase is especially pronounced for state verbs. Y13's use of Preterit is significantly higher than the use of Imperfect for all classes (including activities) except for states where Imperfect was used more frequently $(40.6 \%)$ than Preterit $(28.6 \%)$ (the difference approaches significance: $p=.06$ ). The most interesting result is that this group is more likely to use Preterit if the verb is an achievement, an accomplishment or an activity (i.e. if the verb is [+dynamic]) than if it is a state. Similarly, this group is more likely to use the Imperfect if the verb is a state ([-dynamic]) than if it is an event. This result is, again, in clear contrast with the expected spreading of use of these forms across lexical classes suggested by the LAH and shows that telicity does not affect the pattern of use of Preterit and Imperfect for this group.

The results for the UG (advanced) group reveal the first observable effects of lexical class (telicity in particular) in the use of Preterit and Imperfect as the average use differs significantly across most of the classes (see Figure 4). 


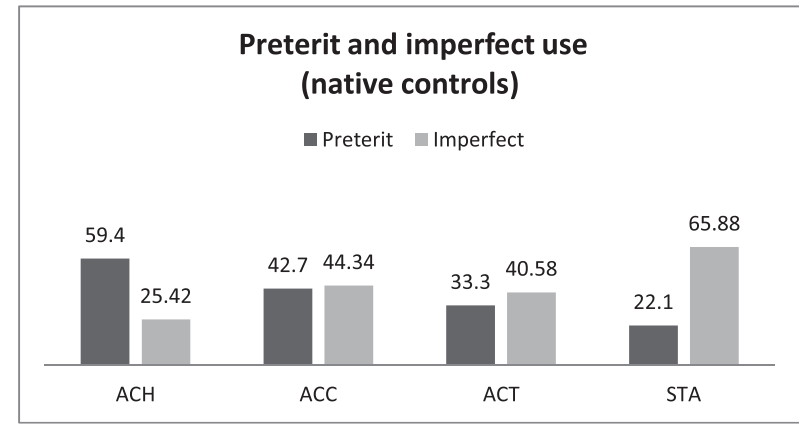

Figure 5. Average use of Preterit and Imperfect in the three oral tasks for native controls.

The use of Preterit is higher with achievements $(69.5 \%)$ than with any other class and decreases to $60.7 \%$ with accomplishments, $42 \%$ with activities and $28.4 \%$ for states. All differences are significant except for that between the telic classes (achievements and accomplishments: $p=.18$ ). Similarly, the Imperfect is only used $16.7 \%$ with achievements and $24.2 \%$ with accomplishments (the two telic classes) whereas its use increases to $30.1 \%$ with activities and $58.3 \%$ with states, as also predicted by the LAH (although the difference between accomplishments and activities for the use of Imperfect is not significant: $p=.23$ ). In contrast to the other two learner groups, the use of Imperfect is for the first time significantly higher than the use of Preterit for states $(p<.001)$.

The reported pattern of use of Preterit (Preterit is most frequently used with telic events and least frequently used with atelic events) is also observed in the results obtained by the native group (see Figure 5). However, even though the difference in use of Imperfect with achievements and states is highly significant $(p<.001)$, no significant difference was found between accomplishments and activities $(p=.54)$. Furthermore, the use of Preterit and Imperfect is not significantly different for accomplishments $(p=.82)$ and activities $(p=.15)$ showing that native speakers did not prefer one of these forms significantly more often for these two classes.

Overall, these results indicate that the combined use of Imperfect and Preterit for each of the lexical classes in the three oral tasks shows clear differences between the beginner and Y13 learners on the one hand, and the advanced learners and native controls on the other. While intermediate and beginner learners do not show the spreading pattern expected by the LAH for either of the two forms, the other two groups do show a pattern which seems consistent with this hypothesis especially for the most prototypical classes (achievements and states).

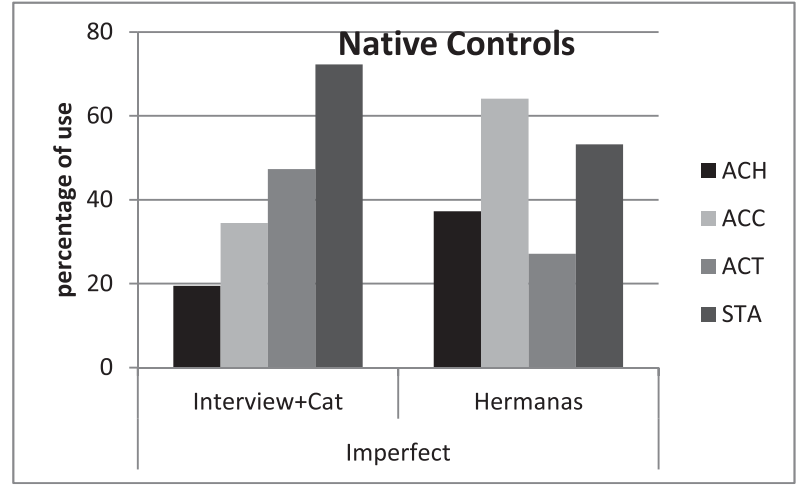

Figure 6. Use of Imperfect according to four lexical classes in two tasks (native controls).

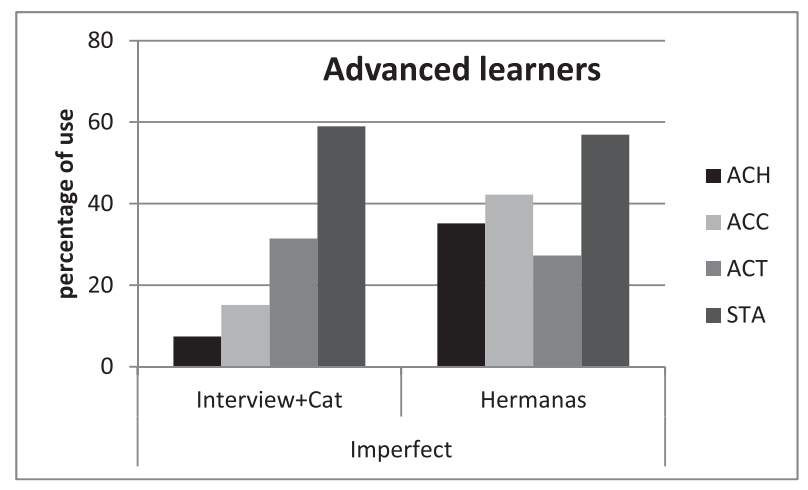

Figure 7. Use of Imperfect according to four lexical classes in two tasks (advanced learners).

\subsection{Use of Imperfect in non-prototypical contexts}

In contrast to previous studies, the results reported in our study include those elicited by a controlled narrative (Las Hermanas) designed to push learners to produce Imperfect and Preterit forms in non-prototypical contexts. Therefore, it is important to examine how far this task influenced the use of these two forms. Next, a comparison is presented between the results obtained by this task and those obtained from the personal narrative and the Cat Story.

The results show striking differences. Figure 6 (native controls) and Figure 7 (advanced L2 speakers) demonstrate how these two groups used the Imperfect according to the pattern predicted by the LAH for the four lexical classes in the personal narrative and Cat Story tasks. In contrast, Las Hermanas was successful in altering this pattern in both groups and eliciting higher use of the Imperfect with telic classes and lower use with atelic classes.

These results allow us to see that the use of Imperfect by native speakers, as well as by advanced L2 speakers, only follows the predicted pattern of the LAH if the type of narrative context is not controlled. The following examples illustrate the use of Preterit with atelic verbs (examples 
(3) and (5)) and Imperfect with telic verbs (examples (4) and (6)) in the Las Hermanas task by one intermediate (Y13-50) and one advanced learner (UG-75):

(3) De repente en tren [había un gran revuelo ${ }_{\text {STATE-IMP }}$ ]

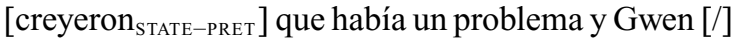
Gwen [sintió agua de lluvia STATE-PRET $_{\text {I }}$ um [necesitió ayuda del revisor STATE-PRET $_{\text {. }}$.

"Suddenly on the train there was a big commotion. They thought there was a problem and Gwen felt raindrops um she needed help from the conductor."

(4) Gwen de niña [leía un libro $_{\text {AссомP-IMP }}$, [pintaba un cuadro $_{\text {ACCOMP-IMP }}$ ] y [escribía un cuento ACCOMP-IMP $_{\text {. }}$ cada fin de semana. Durante la semana [se despertaba temprano ACHIEV-IMP $_{\text {y }}$ y terminaba sus deberes $\left._{\text {ACHIEV-IMP }}\right]$ temprano también.

(Y13-50)

"Gwen when she was a child would read a book, paint a picture, write a story each weekend. During the week she used to wake up early and used to finish her homework early too."

(5) $\mathrm{Y}$ de repente en el tren mientras que [hablaba sobre su niñez $z_{\text {ACTIVITY-IMP }}$ [ [hubo un gran Xx revuelo STATE-PRET $_{\text {. }}$.

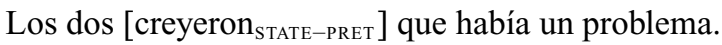

(UG-75)

"And suddenly while they were talking about their childhood there was a big commotion. Both thought that there was a problem."

(6) Gwen de niña cada fin de semana [leía un libro $_{\text {АссомP-IMP }}$, [pintaba un cuadro $_{\text {АссомP-IMP }}$ [ [escribía un cuento $\left.{ }_{\mathrm{AcCOMP-IMP}}\right]$ y durante la semana [se despertaba temprano $\left.{ }_{\text {ACHIEV-IMP }}\right]$.

(UG-75)

"Gwen when she was a child each weekend would read a book, paint a picture, write a story, and during the week she would wake up early."

It is interesting to note how despite the fact that advanced speakers produced slightly fewer Imperfect forms with activities in Las Hermanas (27\%) than in the other two oral tasks combined $(31 \%)$, their use of Imperfect with states was hardly altered between tasks (59\% produced in the personal narrative and Cat Story and $57 \%$ produced in Las Hermanas), but it was for the native speakers $(72 \%$ compared to $53 \%)$. This result is revealing of the strength of the Imperfect-state association already observed in the oral data discussed in the previous section.

The results for the intermediate group (see Figure 8) also show a modified pattern of responses in non-

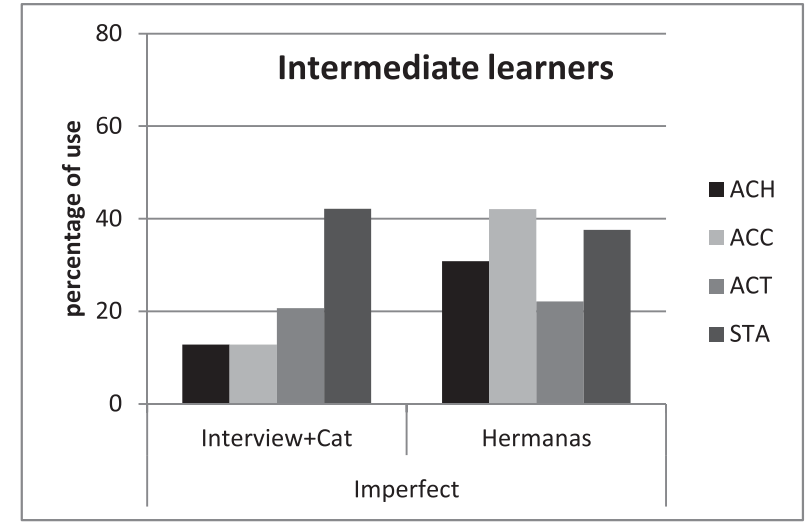

Figure 8. Use of Imperfect according to four lexical classes in two tasks (intermediate learners).

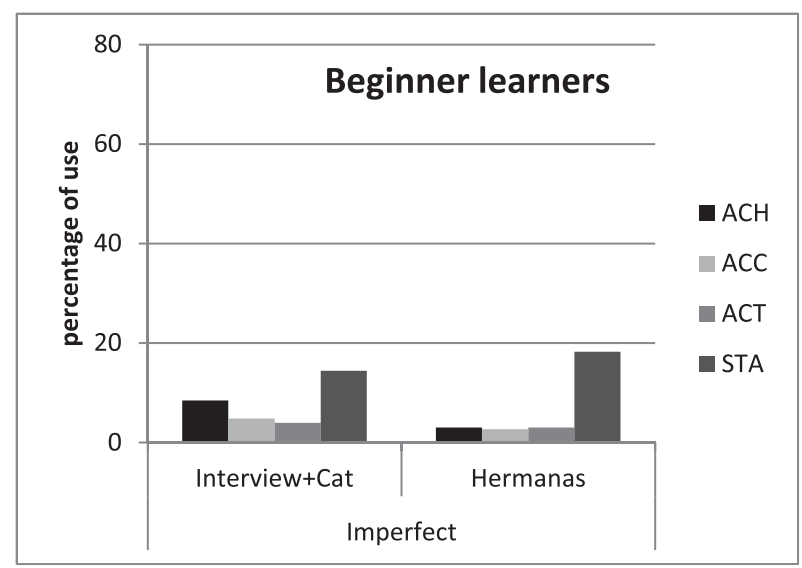

Figure 9. Use of Imperfect according to four lexical classes in two tasks (beginner learners).

prototypical contexts. However, and similarly to the advanced group, the use of Imperfect with states was similar in both sets of tasks $(42 \%$ in personal narrative and Cat Story and 38\% in Las Hermanas) and this was observed for activities $(21 \%$ in personal narrative and Cat Story and 22\% in Las Hermanas) as well.

Overall, these results highlight the resilience of the Imperfect-state association in the grammar of these speakers. The results from the beginner group, which are shown in Figure 9, indicate that this association is observable from the earliest stages of acquisition. As we see in Figure 9, this group prefers to use Imperfect with states in both sets of tasks. In fact, the use of Imperfect was highest in Las Hermanas (18\%).

Overall, the results from this study can be taken as evidence that a strong Imperfect-state association guides the use of this form by L2 Spanish speakers from early on, and that the overall distribution of use of both Preterit and Imperfect cannot be fully accounted for by the LAH. This is particularly the case when we consider that the pattern of spreading across classes predicted by this hypothesis 
Table 7. SCMT design.

\begin{tabular}{llll}
\hline \hline Situation & Context & Type of verb & Target form \\
\hline 1 & Habitual & Eventive & Imperfect \\
2 & Habitual & Stative & Imperfect \\
3 & One-time event & Eventive & Preterit \\
4 & One-time event & Stative & Preterit \\
5 & Continuous & Stative & Imperfect \\
6 & Progressive & Eventive & Imperfect \\
7 & Progressive & Eventive & Imperfect \\
& & (achievements) & \\
\hline \hline
\end{tabular}

one-time-event context, the reverse pattern is expected (high acceptance scores for Preterit and low acceptance scores for imperfect). These predictions are proposed under the assumption that whether the verb is an event or a state plays no role in the acquisition of these forms.

In contrast, any differences in responses across verb types would indicate an influence of dynamicity (the feature which explains the stative/eventive distinction). In particular, if learners are sensitive to the [+/-dynamic] distinction they would tend to accept the Imperfect more often with states than with events and would tend to reject the Preterit with states more often than with events. Crucially, in one-time-event contexts we should find evidence of higher acceptance of the Preterit with event verbs than with states and higher rejection of the Imperfect with events than with states.

\subsection{Participants}

The same 60 learners who participated in the production study took part in the comprehension study. The control group was formed by a group of 15 native speakers of peninsular Spanish.

\subsection{Task design}

Two sets of variables were included in the task design: type of predicate (eventive or stative) and type of context (one-time event, habitual, progressive, and continuous). These were combined to produce 32 different test items (see Table 7). ${ }^{9}$

The participants were asked to rate the appropriateness of a pair of (Imperfect/Preterit) sentences in a particular context using a five-point Likert scale $(-2,-1,0,+1$, +2 ). Each context was carefully biased toward either the sentence with Preterit (depicting one-time-event actions) or the sentence with imperfective morphology (depicting continuous, habitual, or progressive actions). We are aware that the decision to use English in the description of

9 Results for the last situation (Situation 7) are not discussed in the present study.

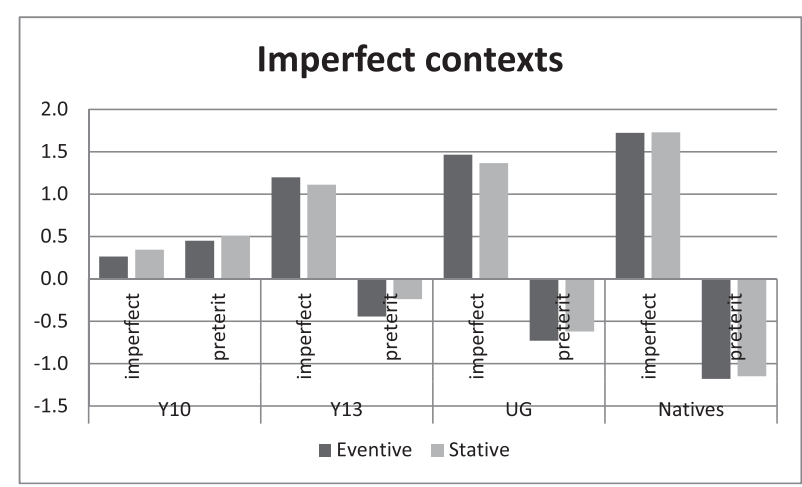

Figure 10. Mean ratings of input sentences in Imperfect contexts.

the situations could have influenced learners' judgements in this task. However, we are not entirely sure that introducing the context in Spanish would have been problem-free either as learners could have based their choices on the Spanish forms available in the descriptions. In the end, due to the wide range of L 2 proficiencies of our participants, we were forced to introduce the situations in the learners' native language to ensure that the less experienced Spanish speakers (the beginner group) could perform this task.

Example (7) illustrates a sample test item where the introductory context represents a habitual action. Sentence (7b), with imperfective morphology, is appropriate in this context.

(7) When Ana was a child she had a very close friend, Amy, and she liked to spend a lot of time at her house after school.

a. Ana estuvo ${ }_{\mathrm{PRET}}$ mucho en casa de Amy al salir del colegio. (inappropriate)

"Ana was in Amy's house a lot after school."

b. Ana estaba ${ }_{\mathrm{IMP}}$ mucho en casa de Amy al salir del colegio. (appropriate)

"Ana used to be in Amy's house a lot after school."

The responses given by each participant were counted and the mean average of each chosen option in each experimental condition was calculated. Mean values were then transformed into percentages. Two types of statistical analyses, within and between groups, were carried out using paired-samples $t$-tests for the former and a one-way ANOVA with Tukey post-hoc tests for the latter.

\subsection{Results}

The results of this study are summarised in Figures 10 and 11. Figure 10 shows the average ratings for both input sentences (with Preterit and Imperfect morphology) in contexts where Imperfect is the appropriate form (i.e. contexts depicting habitual, continuous or progressive actions in the past). Figure 11 shows the average ratings for 
